\title{
Rapid in vitro differentiation of bacteria by ion mobility spectrometry
}

\author{
Isabel Steppert ${ }^{1,2} \cdot$ Jessy Schönfelder ${ }^{1,3} \cdot$ Carolyn Schultz $^{1} \cdot$ Dirk Kuhlmeier ${ }^{1,3}$ \\ Received: 7 October 2020 / Revised: 8 April 2021 / Accepted: 20 April 2021 / Published online: 11 May 2021 \\ (C) The Author(s) 2021
}

\begin{abstract}
Rapid screening of infected people plays a crucial role in interrupting infection chains. However, the current methods for identification of bacteria are very tedious and labor intense. Fast on-site screening for pathogens based on volatile organic compounds (VOCs) by ion mobility spectrometry (IMS) could help to differentiate between healthy and potentially infected subjects. As a first step towards this, the feasibility of differentiating between seven different bacteria including resistant strains was assessed using IMS coupled to multicapillary columns (MCC-IMS). The headspace above bacterial cultures was directly drawn and analyzed by MCC-IMS after 90 min of incubation. A cluster analysis software and statistical methods were applied to select discriminative VOC clusters. As a result, 63 VOC clusters were identified, enabling the differentiation between all investigated bacterial strains using canonical discriminant analysis. These 63 clusters were reduced to 7 discriminative VOC clusters by constructing a hierarchical classification tree. Using this tree, all bacteria including resistant strains could be classified with an AUC of 1.0 by receiver-operating characteristic analysis. In conclusion, MCC-IMS is able to differentiate the tested bacterial species, even the non-resistant and their corresponding resistant strains, based on VOC patterns after 90 min of cultivation. Although this result is very promising, in vivo studies need to be performed to investigate if this technology is able to also classify clinical samples. With a short analysis time of $5 \mathrm{~min}$, MCC-IMS is quite attractive for a rapid screening for possible infections in various locations from hospitals to airports.
\end{abstract}

\section{Key Points}

- Differentiation of bacteria by MCC-IMS is shown after 90-min cultivation.

- Non-resistant and resistant strains can be distinguished.

- Classification of bacteria is possible based on metabolic features.

Keywords Bacteria identification · Volatile organic compounds (VOC) $\cdot$ Ion mobility spectrometry (IMS) $\cdot$ Antibiotic resistance Infection · Diagnostic

\section{Introduction}

Infectious pathogens pose a significant challenge not only to the medical sector but also globally. The worldwide travel

Jessy Schönfelder

jessy.schoenfelder@izi.fraunhofer.de

1 MicroDiagnostics, Fraunhofer Institute for Cell Therapy and Immunology IZI, Leipzig, Germany

2 Institute for Biochemistry and Biology, University of Potsdam, Potsdam, Germany

3 Project Hub Microelectronic and Optical Systems for Biomedicine MEOS, Fraunhofer Institute for Cell Therapy and Immunology IZI, Erfurt, Germany rapid global spreading of infectious pathogens within a few days (Olsen et al. 2003; Khan et al. 2009). Besides viruses, spreading of multi-resistant bacteria from one country to another has been reported as well (Molton et al. 2013). In the Netherlands, every admitted foreign patient is screened for multi-resistant bacteria to prevent nosocomial infections (Gunnink et al. 2021). Such control policy has contributed to low incidence of methicillinresistant Staphylococcus aureus (MRSA) infections in Netherlands. Consequently, new rapid tests are extremely sought after to screen for infected subjects on site.

Currently, the standard diagnostic testing of bacteria is based on cultivation and molecular biological methods. Cultivation techniques belong to the core methodology for diagnosis of bacterial infections but it takes days until the results are available (Laupland and Valiquette 2013). To 
minimize the testing time, genome-based methods like PCR, next-generation-sequencing, and proteome-based matrixassisted laser desorption ionization-time of flight mass spectrometry (MALDI-TOF-MS) have been developed (van Belkum et al. 2013). Despite the short testing time ranging from $1 \mathrm{~h}$ up to 1 day, these tests are still time-consuming and are usually not performed at the point of care. Moreover, these methods are cost-intensive and require many consumables which render them unusable on a grand scale. Consequently, there is an extreme demand for a cost-effective and sensitive analytical device as point of care tool which can detect relevant infections within only some minutes.

On the metabolic level, infectious diseases can be identified based on volatile organic compounds (VOCs) in exhaled breath (Ruszkiewicz et al. 2020; Kunze-Szikszay et al. 2019). VOCs are emitted as gaseous metabolites during the metabolism and provide information about the physiological condition of an organism (Shirasu and Touhara 2011). Recently, many in vitro as well as in vivo studies have proven that different pathogens or diseases result in characteristic combination of VOCs (Hong-Geller and Adikari 2018). Hence, there is a high chance to detect disease-specific VOCs as biomarkers even before the first symptoms occur (Traxler et al. 2018).

Various analytical techniques have been applied for investigating VOCs. The most widely used method is mass spectrometry. Gas chromatography coupled to mass spectrometry (GC-MS) is the gold standard but is quite elaborate in analysis, bulky and requires experts with high expertise (Mathew et al. 2015). In contrast, electronic noses are portable and easy to use. They consist of chemical sensors, which technically imitate the smelling. However, they are limited in quantification precision due to cross reactivity and suffer from sensor ageing (Wilson 2015). Ion mobility spectrometry (IMS) on the other hand has many advantages for diagnostics. It is fast and very sensitive with detection limits of down to parts-per-trillion (ppt) (Westhoff et al. 2009; Hong-Geller and Adikari 2018). In addition, it is already used as on-site tool for the detection of chemical warfare agents, explosives, and drugs at airports (Hopfgartner 2019). Coupling IMS with gas chromatographic columns such as multi-capillary columns (MCC) enhances the separation of complex gas mixtures and provides higher discriminatory power (Cumeras et al. 2015). Due to easy handling and portability, IMS is an ideal candidate for on-site breath analysis. Although laborious, it is even possible to chemically identify the analytes if reference measurements are available. Chemical identification may facilitate a causal interpretation of the results by giving further information about underlying metabolic processes. Nevertheless, pattern recognition may be sufficient for the identification of diseases if the chemical identity of VOCs as biomarkers is known (Westhoff et al. 2009).
While many studies on infection- or pathogen-related VOCs were performed with mass spectrometry technologies, only a few studies have been conducted with ion mobility spectrometry. A differentiation between different bacterial strains and controls in headspace above cultures could be achieved from 2 up to $24 \mathrm{~h}$ of incubation (Jünger et al. 2012; Kunze et al. 2013; Steppert 2013; Drees et al. 2019). Slowly growing mycobacteria could be detected with differential ion mobility spectrometry (DMS) after 1 week of cultivation. Compared to that the identification of mycobacteria using classical culturing techniques takes about 6 weeks (Purkhart et al. 2017). In an in vivo study, Sahota et al. revealed that patients with tuberculosis could be differentiated from the healthy control group with a sensitivity and specificity of about $80 \%$ based on VOCs in exhaled breath by field asymmetric ion mobility spectrometry (FAIMS) (Sahota et al. 2016).

The goal of our research is to develop an IMS-based method for the rapid identification of infectious pathogens that can be used for on-site breath analysis. As a first step towards this goal, this study investigated bacterial cultures in vitro due to a better reproducibility compared to in vivo tests. Within this study, the general feasibility to differentiate several bacterial strains with MCC-IMS should be proven. Besides five bacterial strains from different genera and families, two resistant strains were included to analyze if these can be differentiated from their corresponding sensitive strain. The successful differentiation of in vitro cultures will allow subsequent studies with more complex clinical samples and breath from infected patients.

\section{Materials and methods}

\section{Bacterial strains and sample preparation}

This study includes five bacterial species which are commonly found in infections. These are E. coli (DSM 1576), S. aureus (DSM 346), P. aeruginosa (DSM 1117), K. pneumoniae (DSM 30104), and A. baumannii (DSM 30007). For investigating the differences in VOC patterns between non-resistant and resistant bacteria, this study includes two antibioticresistant strains, methicillin-resistant $S$. aureus (DSM 13661 ), and extended-spectrum beta-lactamase (ESBL) producing K. pneumoniae (DSM 26371). Both resistant strains are used as reference strains for testing antimicrobial resistance according to Clinical and Laboratory Standards Institute (CLSI), and thus, they were used in this study. Resistance in this MRSA strain DSM 13661 is regulated by the gene mecA located in the staphylococcal cassette chromosome mec (SCCmec) which codes for a modified penicillin-binding protein (PBP2a) with low affinity for beta-lactam antibiotics (Kwiatkowski et al. 2020; Peacock and Paterson 2015). 
All bacterial strains were cultivated overnight on tryptic soy agar plates at $37^{\circ} \mathrm{C}$. Afterwards they were sub-cultured in 30-ml tryptic soy broth (TSB) (Oxoid Limited, Hamphire, UK) and incubated for $20 \mathrm{~h}$ with constant agitation at $37^{\circ} \mathrm{C}$. On the day of the MCC-IMS measurements, starting cultures with an initial bacterial concentration of 0.1 optical density at $600 \mathrm{~nm}\left(\mathrm{OD}_{600}\right)$ were gained from subcultures. An amount of $5 \mathrm{ml}$ of the starting cultures were transferred into $20-\mathrm{ml}$ autoclaved headspace vials (Macherey-Nagel, Düren, Germany) and sealed with autoclaved PTFE/silicone septum caps (Macherey-Nagel, Düren, Germany). Headspace vials with 5-ml pure TSB were prepared as control samples. All filled headspace vials were incubated at $37{ }^{\circ} \mathrm{C}$ in a heating block for 90 min until the start of the analysis with MCC-IMS.

To ensure the reproducibility of the method, the sample preparation and MCC-IMS measurements were performed for each non-resistant strain and control at three different days (day $1, n=5$; day 2, $n=3$; and day 3, $n=3$ ). Ten replicates of each resistant strain were used.

\section{MCC-IMS analysis}

The VOCs emitted by bacteria into the headspace above cultures were analyzed with an ion mobility spectrometer coupled to a multi-capillary column (MCC-IMS) from STEP (Sensortechnik und Elektronik Pockau GmbH, Pockau, Germany). This device contains an internal gas circulation with a filter, which is regulated by a circulation pump to provide filtered ambient air as drift gas $(400 \mathrm{ml} / \mathrm{min})$ as well as analysis gas $(20 \mathrm{ml} / \mathrm{min})$. The whole experimental set up for this study is visualized in Fig. 1.
From the headspace of each sample vial, $10 \mathrm{ml}$ were drawn via a 30-cm PTFE tube into a heated $0.7-\mathrm{ml}$ sample loop (50 ${ }^{\circ} \mathrm{C}$ ) by an internal pump with a flow rate of $200 \mathrm{ml} / \mathrm{min}$. Therefore, the septum of the headspace vial was punctured with two cannulas. One cannula was used for VOC sampling and the other for pressure equalization in the headspace vial. The latter cannula is connected to an activated carbon filter to avoid interfering organic substances. After sampling, the gaseous analytes were pre-separated by the isothermally heated $\left(40{ }^{\circ} \mathrm{C}\right)$ multi-capillary column $(\mathrm{OV}-5,20 \mathrm{~cm}$, Multichrom Ltd., Novosibirsk, Russia) and finally migrated into the IMS unit based on their retention times. There, they were initially ionized by a radioactive tritium source $(99 \mathrm{MBq})$. Afterwards, the generated charged ions were accelerated by an electrical field $(400 \mathrm{~V} / \mathrm{cm})$ towards the heated detector $\left(60^{\circ} \mathrm{C}\right)$ against the drift-gas flow. Due to collisions with drift gas molecules, ions were separated based on their mobility measured as drift time. The IMS can record positive or negative ions. For this study, the positive ion mode was applied. The basic working principle of IMS has been described in Stach and Baumbach (2002).

\section{MCC-IMS data analysis}

The entire dataset consists of 86 measurements. During each measurement, 253 raw IMS spectra were recorded, i.e., one IMS spectrum at each second of MCC retention time. Within this time, all relevant headspace VOCs could be expected to be detected (Jünger et al. 2012; Kunze et al. 2013). All raw spectra together form a two-dimensional matrix where peaks are depicted as signal intensity in volts $(\mathrm{V})$ depending on the

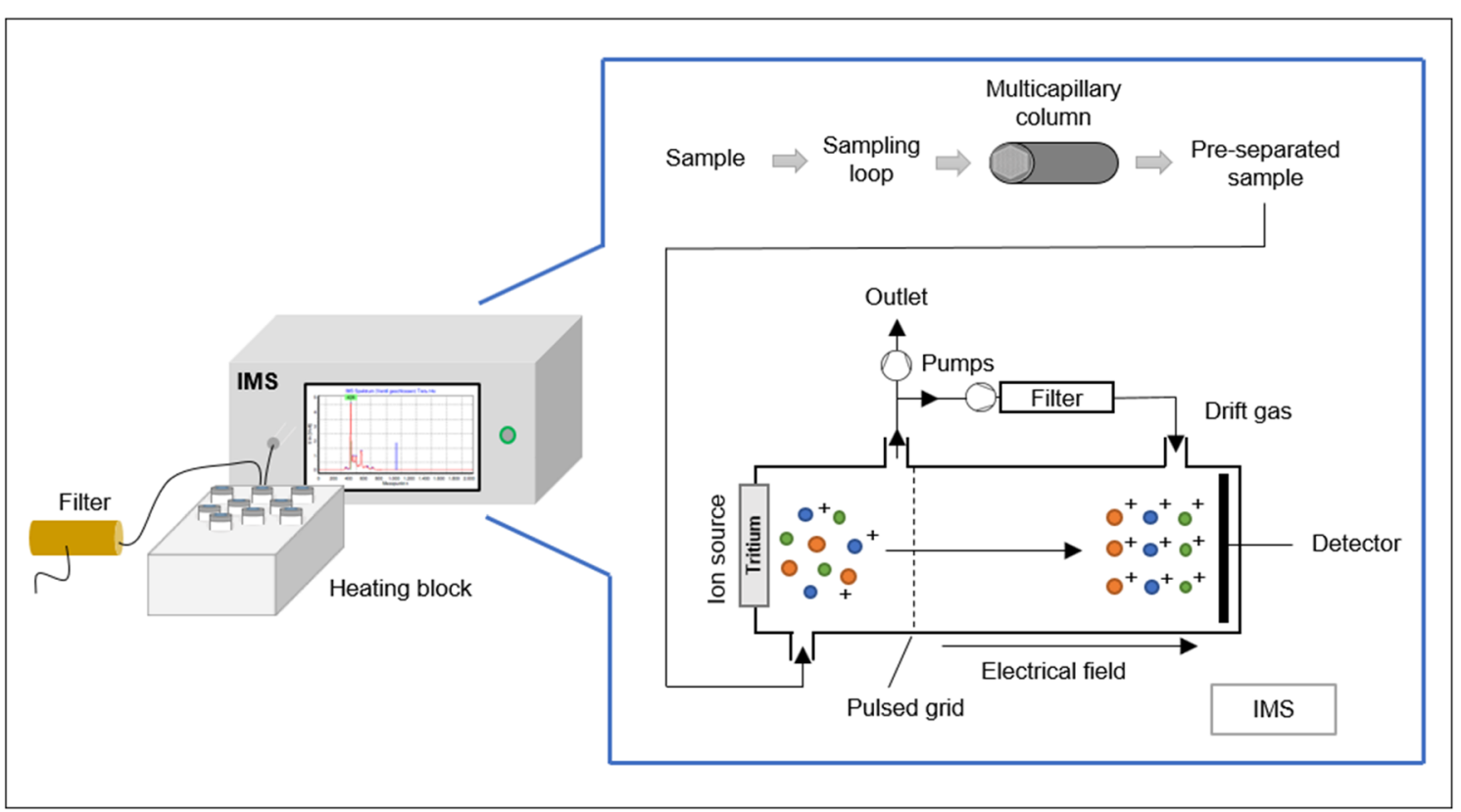

Fig. 1 Schematic drawing of the setup for sampling and IMS measurement of bacterial cultures in headspace vials (modified from the manual, version 10.2017, of the used IMS device) 
retention time in seconds (s) on the $y$-axis and drift time in milliseconds (ms) on the $x$-axis as seen in Fig. 2. For data analysis, the pattern of peaks was considered. Thus, dimers and trimers have not been taken into account. All peaks together form the VOC pattern of the sample.

To differentiate between different bacterial strains based on their distinct VOC patterns, the raw MCC-IMS spectra of all measurements were processed with a proprietary clusteranalysis software. The analysis principle of this software is described in Purkhart et al. (2011), Purkhart (2010), and Becher et al. (2012). In brief, this software integrates data pre-processing steps (background adjustment, smoothing), peak detection based on local maxima calculation, and a hierarchical clustering algorithm to account for varying peak positions of the same VOC in different measurements (Purkhart et al. 2011; Purkhart 2010; Becher et al. 2012). This is based on the assumption that every cluster represents one VOC. The generated clusters can be used as a parameter for comparing sample groups as well as for statistical analysis. In this study, only peaks with a signal intensity higher than $0.05 \mathrm{~V}$ were registered.

\section{Statistical analysis}

The resulting VOC clusters were analyzed using descriptive and multivariate statistical methods (IBM SPSS Statistics, Version 26.0, IBM Corp., Armonk, NY, USA; Stata Statistical Software: Release 11, StataCorp LP, College Station, TX, USA). Signal intensities in volt (V) of the VOC clusters were used as variables in this statistical analysis. The first step involved picking relevant VOC clusters of non-

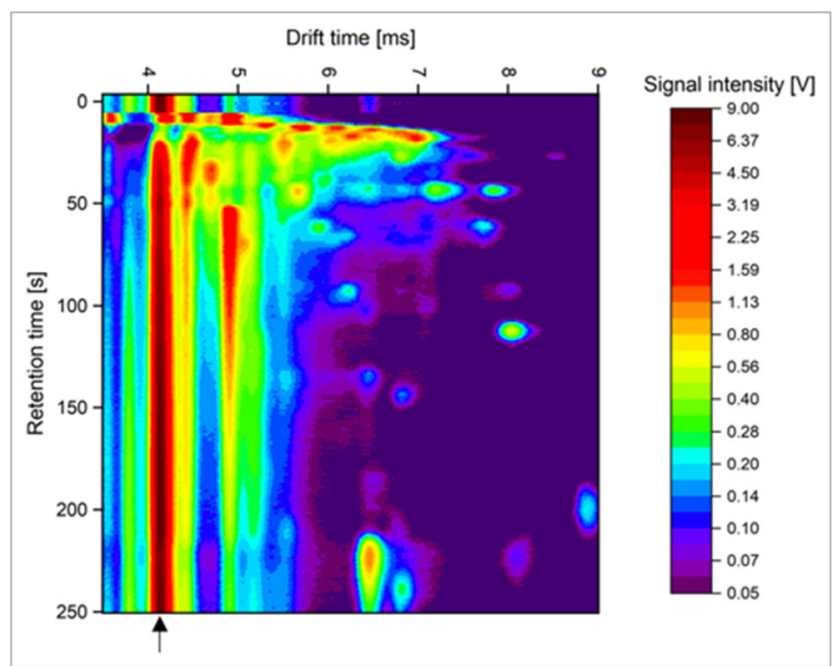

Fig. 2 An exemplary MCC-IMS heatmap of positive charged components of volatile bacterial metabolites. Volatile components are depicted as peaks in signal intensity in volts $(\mathrm{V})$ depending on the retention time in seconds (s) on the $y$-axis and drift time in milliseconds $(\mathrm{ms})$ on the $\mathrm{x}$-axis. The red-brown line (see arrow) at a drift time of $4.14 \mathrm{~ms}$ represents the reactant ion peak which originates from ions from the drift gas and does not correspond to analytes resistant and resistant bacterial strains. A VOC cluster was considered relevant if at least $80 \%$ of replicates had the peak and the median signal intensity was greater than control. To identify VOC clusters significantly differentiating each bacterial strain from control, Wilcoxon rank-sum test was applied. Values of $p \leq 0.05$ were considered significant. With these significant VOC clusters, a canonical discriminant analysis (CDA) was performed. CDA was chosen because it is a widely used classification technique for IMS data and focuses on differences between groups (Szymańska et al. 2016). For visualization of differences, a three-dimensional (3D) scatterplot was created (Origin, Version 2018, OriginLab Corporation, MA, USA).

In order to investigate if each bacterial strain can be classified based on only some specific peaks, a hierarchical classification tree was constructed. This tree could be used to separate bacterial classes based on specific VOC clusters. The receiver-operating characteristic (ROC) curve analysis was applied to find classifiers (VOC clusters) for separation of bacterial classes for the classification tree. Variables used for the ROC analysis were the VOC clusters for which each bacterial strain showed a higher signal intensity compared to control medium (Wilcoxon rank-sum test with $p \leq 0.05$ ) and at least $80 \%$ of their replicates had the peak. The performance of the classifier is determined by the area under curve (AUC). The higher the AUC, the better is the prediction of the classifier. The VOC clusters with highest AUC were selected as classifiers, or decision nodes in the tree. Additionally, different candidate threshold values of signal intensity [V] for a classifier could be obtained by ROC analysis. The threshold value with the highest sensitivity and specificity was used as cut point value for branching in the hierarchical tree.

\section{Results}

The headspace of non-resistant bacterial strains and the control was investigated by applying MCC-IMS on three different days to ensure the reproducibility of the method. A number of 90 VOC clusters from resistant and non-resistant bacterial strains as well as controls had a signal in at least $80 \%$ of replicates and were considered further. Subsequently, VOC clusters with a significantly higher signal in bacteria samples compared to the control were selected assuming that these VOCs were produced by the bacteria. As a result, 63 VOC clusters were identified. Their retention and drift times are listed in Table 1 and their positions in the two-dimensional plot in supplemental Figure S1.

The contribution of each single VOC cluster to the differentiation between non-resistant and resistant bacterial strains is shown in Table 1. It is evident that all seven bacterial strains can be distinguished based on these $63 \mathrm{VOC}$ clusters. Most VOC clusters were found for resistant strains, ESBL 
Table 1 List of 63 VOC clusters for which non-resistant and resistant bacterial strains show a significantly higher signal intensity compared to control medium (Wilcoxon rank-sum test with $p \leq 0.05$ ) and at least $80 \%$ of their replicates have the peak. The VOC clusters are listed with their retention time (RT) in seconds (s) and drift time (td) in milliseconds (ms) as well as their occurrence $(\mathrm{x})$ in the investigated seven different bacterial strains

\begin{tabular}{|c|c|c|c|c|c|c|c|c|c|}
\hline \multirow[b]{2}{*}{ VOC cluster } & \multirow[b]{2}{*}{$\mathrm{RT}(\mathrm{s})$} & \multirow[b]{2}{*}{$\mathrm{td}(\mathrm{ms})$} & \multicolumn{5}{|c|}{ Non-resistant bacterial strains } & \multicolumn{2}{|c|}{ Resistant bacterial strains } \\
\hline & & & $\mathrm{EC}$ & MSSA & PA & $\mathrm{KP}$ & $\mathrm{AB}$ & MRSA & KP ESBL \\
\hline c_1 & 2 & 5.28 & & & & & & $\mathrm{x}$ & \\
\hline c_2 & 6 & 4.49 & $\mathrm{x}$ & & & $\mathrm{x}$ & & & $\mathrm{x}$ \\
\hline c_3 & 8 & 5.01 & $\mathrm{x}$ & & & $\mathrm{x}$ & & $\mathrm{x}$ & $\mathrm{x}$ \\
\hline c_4 & 9 & 4.75 & & & $\mathrm{x}$ & & & & \\
\hline c_5 & 11 & 5.37 & & & & & & $\mathrm{x}$ & $\mathrm{x}$ \\
\hline c_6 & 12 & 5.75 & & & & $\mathrm{x}$ & & & $\mathrm{x}$ \\
\hline c_7 & 13 & 6.18 & & & & & & $\mathrm{x}$ & \\
\hline c_8 & 17 & 6.04 & $\mathrm{x}$ & $\mathrm{x}$ & & & & $\mathrm{x}$ & $\mathrm{x}$ \\
\hline c_9 & 17 & 6.33 & $\mathrm{x}$ & & & $\mathrm{x}$ & $\mathrm{x}$ & & $\mathrm{x}$ \\
\hline c_10 & 17 & 6.88 & & & $\mathrm{x}$ & & $\mathrm{x}$ & & \\
\hline c_11 & 18 & 7.02 & $\mathrm{x}$ & & & $\mathrm{x}$ & & & $\mathrm{x}$ \\
\hline c_12 & 20 & 5.62 & $\mathrm{x}$ & & & $\mathrm{x}$ & $\mathrm{x}$ & & $\mathrm{x}$ \\
\hline c_13 & 21 & 4.55 & $\mathrm{x}$ & & $\mathrm{x}$ & $\mathrm{x}$ & & & $\mathrm{x}$ \\
\hline c_14 & 27 & 5.20 & & & & & & $\mathrm{x}$ & \\
\hline c_15 & 27 & 6.88 & & & & & $\mathrm{x}$ & & \\
\hline c_16 & 32 & 6.30 & & $\mathrm{x}$ & & & & & \\
\hline c_17 & 34 & 4.75 & & $\mathrm{x}$ & $\mathrm{x}$ & & & $\mathrm{x}$ & $\mathrm{x}$ \\
\hline c_18 & 39 & 5.20 & & & & & & $\mathrm{x}$ & \\
\hline c_19 & 39 & 6.01 & $\mathrm{x}$ & & & & & & $\mathrm{x}$ \\
\hline c_20 & 42 & 6.44 & & & & $\mathrm{x}$ & & & $\mathrm{x}$ \\
\hline c_21 & 43 & 6.29 & & & $x$ & & & & \\
\hline c_22 & 43 & 6.87 & & & & $\mathrm{x}$ & & & \\
\hline c_23 & 43 & 7.31 & & & & $\mathrm{x}$ & & & \\
\hline c_24 & 43 & 7.88 & & & & $\mathrm{x}$ & & & \\
\hline c_25 & 44 & 5.73 & & & & $\mathrm{x}$ & & $\mathrm{x}$ & \\
\hline c_26 & 46 & 5.20 & & $\mathrm{x}$ & & & & & \\
\hline c_27 & 49 & 4.47 & $\mathrm{x}$ & & & $\mathrm{x}$ & & & $\mathrm{x}$ \\
\hline c_28 & 53 & 7.69 & & & & & & $\mathrm{x}$ & \\
\hline c_29 & 57 & 4.97 & & & & & & $\mathrm{x}$ & $\mathrm{x}$ \\
\hline c_30 & 57 & 6.66 & & $\mathrm{x}$ & & & & $\mathrm{x}$ & \\
\hline c_31 & 60 & 6.78 & & & & & & & $\mathrm{x}$ \\
\hline c_32 & 60 & 7.14 & & & & & & $\mathrm{x}$ & $\mathrm{x}$ \\
\hline c_33 & 62 & 5.95 & & & & & $\mathrm{x}$ & & \\
\hline c_34 & 67 & 5.54 & $\mathrm{x}$ & & & & & & \\
\hline c_35 & 75 & 4.96 & & & & & & $\mathrm{x}$ & \\
\hline c_36 & 79 & 7.13 & & & & & & & $\mathrm{x}$ \\
\hline c_37 & 83 & 5.54 & $\mathrm{x}$ & & & $\mathrm{x}$ & & & $\mathrm{x}$ \\
\hline c_38 & 88 & 5.94 & & & & & & & $\mathrm{x}$ \\
\hline c_39 & 90 & 6.66 & & $\mathrm{x}$ & & & & & \\
\hline c_40 & 91 & 7.13 & & & & & & $\mathrm{x}$ & \\
\hline c_41 & 93 & 6.23 & & & & & $\mathrm{x}$ & & \\
\hline c_42 & 96 & 5.56 & $\mathrm{x}$ & & & $\mathrm{x}$ & & & $\mathrm{x}$ \\
\hline c_43 & 98 & 7.14 & & & & & & $x$ & \\
\hline c_44 & 106 & 5.55 & $\mathrm{x}$ & & & & & & $\mathrm{x}$ \\
\hline c_45 & 111 & 8.15 & & & & & $\mathrm{x}$ & & \\
\hline
\end{tabular}


Table 1 (continued)

\begin{tabular}{|c|c|c|c|c|c|c|c|c|c|}
\hline \multirow[b]{2}{*}{ VOC cluster } & \multirow[b]{2}{*}{$\mathrm{RT}(\mathrm{s})$} & \multirow[b]{2}{*}{$\mathrm{td}(\mathrm{ms})$} & \multicolumn{5}{|c|}{ Non-resistant bacterial strains } & \multicolumn{2}{|c|}{ Resistant bacterial strains } \\
\hline & & & $\mathrm{EC}$ & MSSA & PA & KP & $\mathrm{AB}$ & MRSA & KP ESBL \\
\hline c_46 & 115 & 4.98 & & & & & & $\mathrm{x}$ & \\
\hline c_47 & 134 & 6.96 & & & & & & $\mathrm{x}$ & \\
\hline c_48 & 135 & 5.64 & & $\mathrm{x}$ & & & & $\mathrm{x}$ & \\
\hline c_49 & 145 & 5.55 & & & & & & & $\mathrm{x}$ \\
\hline c_50 & 162 & 5.22 & & $\mathrm{x}$ & & & & $\mathrm{x}$ & \\
\hline c_51 & 191 & 5.23 & & & & & & $\mathrm{x}$ & \\
\hline c_52 & 208 & 6.82 & $\mathrm{x}$ & & & & & & \\
\hline c_53 & 212 & 5.60 & & & & & & $\mathrm{x}$ & $\mathrm{x}$ \\
\hline c_54 & 223 & 5.57 & $\mathrm{x}$ & & & & & & $\mathrm{x}$ \\
\hline c_55 & 223 & 8.15 & & & & $\mathrm{x}$ & & & \\
\hline c_56 & 225 & 6.53 & & & $\mathrm{x}$ & $\mathrm{x}$ & & & \\
\hline c_57 & 229 & 5.54 & $\mathrm{x}$ & & & $\mathrm{x}$ & & & $\mathrm{x}$ \\
\hline c_58 & 236 & 5.53 & $\mathrm{x}$ & & & & & & $\mathrm{x}$ \\
\hline c_59 & 238 & 4.98 & & & & & & $\mathrm{x}$ & $\mathrm{x}$ \\
\hline c_60 & 239 & 5.23 & & & & & & $\mathrm{x}$ & \\
\hline c_61 & 243 & 5.23 & & & & & & $\mathrm{x}$ & \\
\hline c_62 & 243 & 5.54 & $\mathrm{x}$ & & & & & & $\mathrm{x}$ \\
\hline c_63 & 245 & 4.97 & & & & & & $\mathrm{x}$ & $\mathrm{x}$ \\
\hline
\end{tabular}

producing $K$. pneumoniae (29) and methicillin-resistant $S$. aureus (26). Non-resistant $K$. pneumoniae (18) and E. coli (18) generated more VOCs compared to the other non-resistant strains methicillin-sensitive $S$. aureus (8), A. baumannii (7), and $P$. aeruginosa (6). Some VOC clusters, e.g., c_52 and c_55, could be assigned to only one strain but others like c_2, c_8, and c_10 to several strains, respectively. Interestingly, E. coli shared several VOC clusters with the two strains of $K$. pneumoniae that are not present in the headspace of control or the other bacterial strains (see supplemental Figure S2).

To determine the discrimination between the seven bacterial strains, a canonical discriminant analysis was performed. To visualize the results, a three-dimensional plot (Fig. 3) was created for the first three canonical functions using the selected 63 VOC clusters. In this plot, bacterial strains and controls are represented as colored data points (one data point for each replicate). The presented three canonical functions explain a variance of $99.1 \%$. Figure 3 displays a clear differentiation between all seven bacterial strains including two resistant strains from the control medium. Within the bacterial strains, a separation with highest distances was found for $E$. coli as well as for both strains of $K$. pneumoniae. In contrast, the data points of $S$. aureus (MSSA) and resistant $S$. aureus (MRSA) are in closer proximity. Based on the classification model, all bacterial strains can be assigned to their group $100 \%$ correctly by using leave-one-out cross-validation (see supplemental Table S1).

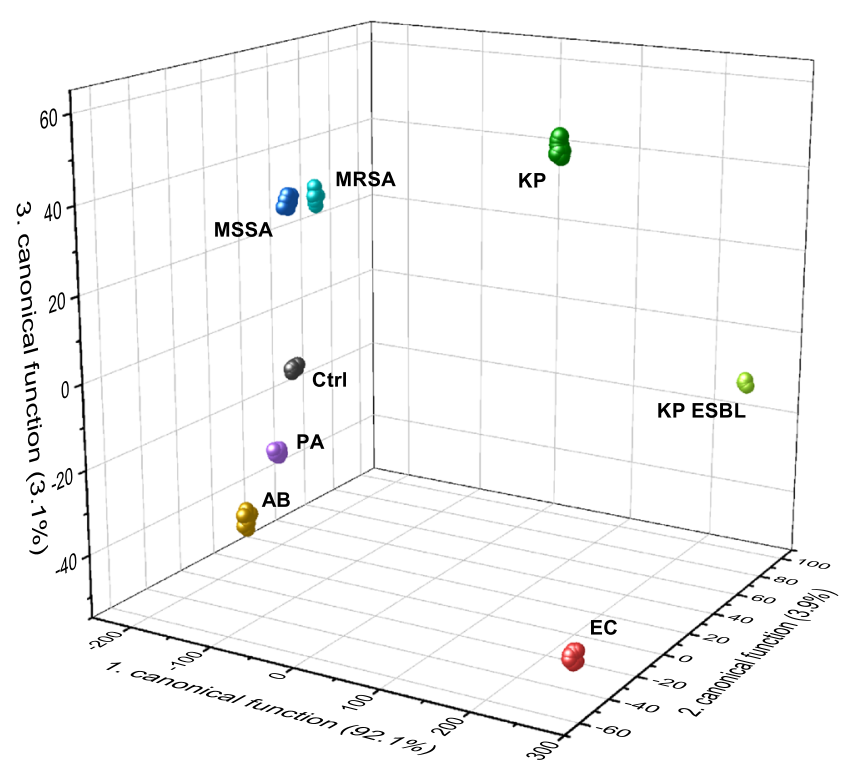

Fig. 3 All 86 measurements from the different bacterial strains and the control are displayed as single data points in a three-dimensional space spanned by the first three canonical functions. These functions are linear combinations of the selected 63 VOC clusters and are explaining already $99.1 \%$ of the variance (first, second, and third canonical function: $92.1 \%$, $3.9 \%$, and $3.1 \%$, respectively). The plot shows a clear discrimination between non-resistant and resistant bacterial strains. Ctrl Control, EC E. coli, MSSA methicillin-sensitive $S$. aureus, PA P. aeruginosa, KP K. pneumoniae, AB A. baumannii, MRSA methicillin-resistant $S$. aureus, KP ESBL extended-spectrum beta-lactamase producing K. pneumoniae 
Alternatively, to the canonical discriminant functions, a hierarchical classification tree was constructed. This classification tree can be used to separate the investigated bacterial classes based on specific VOC clusters, which were selected from the 63 VOC clusters presented in Table 1. By ROC curve analysis the separation of the different bacterial strains could be achieved with an AUC of 1.0. For several bacterial strains, more than one VOC cluster could be used for the dichotomization (see supplemental material). The resulting hierarchical tree with seven VOC clusters (Fig. 4) allows a classification of all bacterial strains. Using cluster c_8 with a cut point of 1.63 $\mathrm{V}$, two classes, the staphylococci and the gram-negative bacteria, were differentiated. Depending on the cluster 2 with a cut point of $1.47 \mathrm{~V}$, gram-negative bacteria could be separated into fermenting (E. coli, K. pneumoniae, and ESBL producing K. pneumoniae) and non-fermenting bacteria (A. baumannii and $P$. aeruginosa). Furthermore, the classification into subsequent classes could be performed by specific VOC clusters according to Fig. 4. In Fig. 5, seven VOC clusters are shown as boxplots that enable classification of certain bacterial strains by using ROC curve analyses.

\section{Discussion}

This study shows that seven bacterial strains including resistant strains can be differentiated by applying MCC-IMS in the headspace of liquid cultures after 90-min incubation. The 63 VOC clusters listed in Table 1 were used as input variables for a canonical discriminant analysis. The discriminant analysis separated and classified the clusters correctly with a success rate of $100 \%$. Moreover, using seven VOC clusters, a hierarchical classification tree was able to distinguish all investigated bacterial strains with an AUC of 1.0 by ROC curve analysis. Nevertheless, it has to be considered that the classification tree is prone to overfitting and might not be suitable for real and unknown data as only one strain per species was investigated. Therefore, the results need to be validated on patient derived samples.

Only few studies used IMS to explore the feasibility of fast bacteria identification. Drees et al. (2019) investigated VOCs emitted by E. coli, S. aureus, and P. aeruginosa in headspace of blood cultures using GC-IMS hourly for up to $8 \mathrm{~h}$ of incubation. Their results revealed that the best differentiation could be achieved after $6 \mathrm{~h}$ of incubation. Kunze et al. (2013) studied the VOCs related to the growth of E. coli and P. aeruginosa in lysogenic broth as a culture medium using MCC-IMS. The differences between them were observed in the logarithmic and stationary phase. Compared to these two studies, we achieved a differentiation as early as $90 \mathrm{~min}$ after inoculation. It can be assumed that a higher concentration of bacteria may lead to an earlier occurrence of VOCs and therefore to an earlier differentiation by headspace analysis with IMS. Unfortunately, Drees et al. (2019) and Kunze et al. (2013) did not specify the start concentration of the bacteria cultures, although it is apparent that both studies used an initial bacteria suspension with a much lower OD. Therefore, the differentiation in such an early stage in our study might be due to the high initial bacteria concentrations. In addition, the OD value of 0.1 used in our study results in a

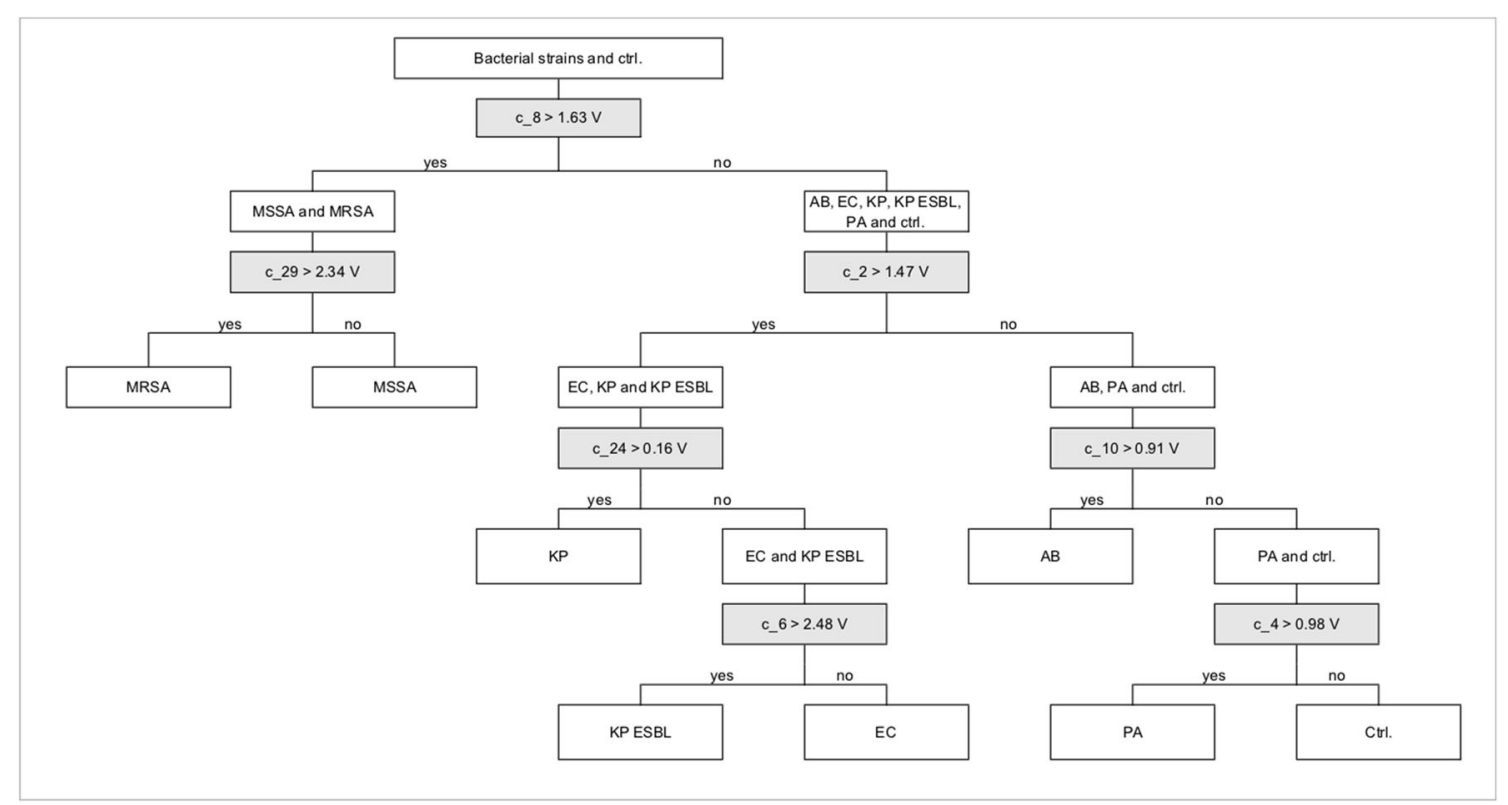

Fig. 4 Hierarchical classification tree with seven VOC clusters. This tree allows for a classification of the investigated bacterial strains using specific VOC clusters. Grey boxes present the VOC clusters with cut point value in volt (V) serving as decision variable for splitting respective classes into sub-classes. Ctrl. Control, EC E. coli, MSSA methicillin-sensitive $S$. aureus, PA P. aeruginosa, KP K. pneumoniae, AB A. baumannii, MRSA methicillin-resistant $S$. aureus, KP ESBL extended-spectrum beta-lactamase producing $K$. pneumoniae 
Fig. 5 Boxplots of seven VOC clusters that allow a classification of different bacterial strains by using classification tree approach. EC E. coli, MSSA methicillinsensitive $S$. aureus, PA $P$. aeruginosa, $\mathrm{KP}$

K. pneumoniae, $\mathrm{AB}$

A. baumannii, MRSA methicillinresistant $S$. aureus, KP ESBL extended-spectrum betalactamase producing K. pneumoniae
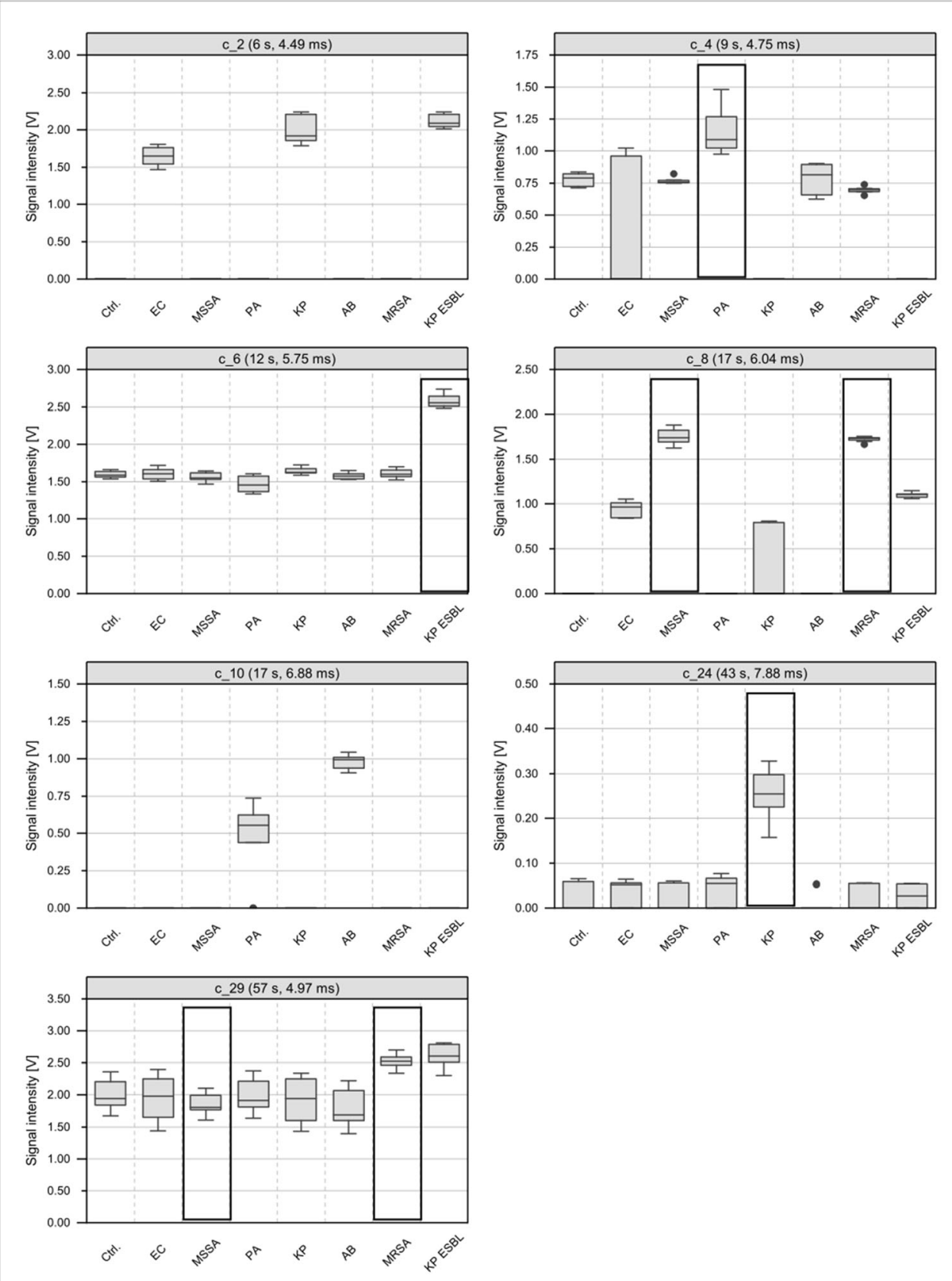

quite high bacteria concentration and might not reflect cell numbers in clinical settings.

With IMS positive and negative ions can be detected. We used the positive ion modes only. The need for negative ions may depend on the amount of VOCs present after different incubation times. For the differentiation of 15 different human pathogenic bacteria after $24 \mathrm{~h}$ of incubation, Jünger et al. (2012) required the negative ion mode in addition to the positive one. Our restriction to positive ion mode is in line with the study of Drees et al. (2019) where only one VOC in negative ion mode could be detected for $E$. coli within the first $8 \mathrm{~h}$ of incubation. This aspect could be confirmed by an earlier study (Steppert 2013) in which the negative ion mode rarely delivered information compared to the positive ion mode. Moreover, this study showed that the number of bacterial VOCs dropped drastically after $6 \mathrm{~h}$ of incubation (Steppert 2013). It may be assumed that after $24 \mathrm{~h}$ of incubation, there was a substrate depletion leading to lower concentration of VOCs.

This study focused on VOCs, which are produced by the bacteria. Therefore, only VOC clusters with a higher intensity in bacterial samples compared to the culture medium control were included. There might be even more relevant VOC clusters if clusters would have been considered that exhibit a lower 
intensity in bacterial samples than control samples indicating consumption of culture medium components.

Our data demonstrated that some VOCs are released not only by one but also by different bacterial strains. Our findings are in accordance with Boots et al. (2014) who revealed that one specific VOC may not be sufficient for distinguishing different bacterial species. Moreover, the released bacterial VOCs might also depend on available nutrients or growth medium (Küntzel et al. 2016; Ratiu et al. 2017). Thus, for a reliable differentiation, further studies need to be performed.

The obtained hierarchical classification tree supports the hypothesis that the differentiation by VOCs depends on the metabolic features of the different bacteria. Thus, we assume that the use of bacterial VOCs for species identification can be applied similar to the principle of the analytical profile index (API) system. The API system relies on classifying bacteria based on metabolic characteristics in an array of biochemical tests. For example, the differentiation between Enterobacteriaceae and non-Enterobacteriaceae within gram-negative rods depends on the presence or absence of oxidase and therefore on the fermentation ability of sugars. In our study, several distinct VOCs appeared that differ between fermenters and non-fermenters. However, the presented classification tree applies only for the bacterial species investigated in this study. In order to confirm the above-mentioned hypothesis, more members of different bacteria families will have to be investigated.

Several studies that have been published as conference abstracts only could also show that even resistant strains can be differentiated from non-resistant strains by IMS (Steppert et al. 2018; Becher et al. 2016). The discrimination of resistant bacteria by means of their VOCs was also confirmed by other studies with mass spectrometry (Boots et al. 2014; Rees et al. 2018). It remains unclear, if the difference of VOC patterns originates from metabolic shift induced by the resistance mechanism itself or from using two different strains for resistant and susceptible bacteria with different metabolic features. To clarify this, other approaches than VOC pattern recognition should be considered since the knowledge of the identity of the differentiating VOCs might help if these could be connected to certain metabolic processes. However, chemical identification with IMS is laborious and reference measurements are needed. Nonetheless, similar results in several studies imply that the VOC difference between MSSA and MRSA as well as $K$. pneumoniae versus extended-spectrum betalactamase producing $K$. pneumoniae may be based on an altered metabolism triggered by the resistance mechanism. In the other studies (Steppert et al. 2018; Becher et al. 2016; Steppert 2013), this was consistently found in clinical isolates. It can be assumed that different resistant mechanisms like cleaving of antibiotics may also produce different volatile metabolites compared to non-resistant strains (Tenover 2006). To answer this question conclusively, studies with strains before and after transfections of resistance genes should be undertaken. Therefore, the VOC pattern recognition approach might even be sufficient without the need of substance identification, although the latter still might give more background information.

In most VOC analysis studies, offline methods like solid phase microextraction (SPME) and desorption tubes are used to sample VOCs (Wilde et al. 2019; Pereira et al. 2014). With regard to on-site screening, those methods are quite elaborate due to a long enrichment period of about $30 \mathrm{~min}$ and require an additional thermal desorption unit to release VOCs for analysis. Therefore, we chose direct analysis by drawing the VOCs into the system by an internal pump. Altogether, sampling and analysis took only $4 \mathrm{~min}$. In addition, this method does not require expert knowledge and is convenient due to easy handling and a low waiting time required to receive the results. Compared to other IMS devices, the utilized STEP-IMS device does not need synthetic gases. This reduces consumables and enables on-site analyses.

Compared to Drees et al. (2019) and Jünger et al. (2012), we did not perform mass spectrometry in addition to IMS to identify the VOCs chemically, although this might be helpful to explain the origin of the VOCs. However, at this stage, the aim of the study was to show the identification of bacteria based on VOC patterns. There are successful attempts to train animals like dogs and rats to smell infections of resistant bacteria and tuberculosis, respectively (Koivusalo et al. 2017; Fiebig et al. 2020). Identification of VOCs by animals relies on the recognition of VOC patterns or a number of specific VOCs of this pattern that are responsible for the scents. Hence, it should be possible to show the identification of bacteria based on certain compositions of VOC clusters in the form of patterns without knowing the substance identity of each single VOC.

To support a reliable analysis with MCC-IMS, we measured the same bacterial strain several times on three different days in order to obtain the most distinctive VOC clusters and to eliminate random influences. Nevertheless, only reference strains in small sample sizes were investigated which constitutes a limitation of this study. Moreover, the clinical relevance of these reference strains is limited. Further investigations on clinical isolates of different bacterial species on a greater scale should be conducted to confirm the ability of MCC-IMS method to identify specific species based on VOC patterns.

In conclusion, this study demonstrates that MCC-IMS was able to differentiate reference strains of seven different bacterial species including resistant species based on VOC patterns after $90 \mathrm{~min}$ of incubation by applying canonical discriminant analysis. Sampling and MCC-IMS- analysis took only $4 \mathrm{~min}$. 
Moreover, the study shows that discriminative VOCs can be assigned to specific species based on their metabolic characteristics using a classification tree, even without knowing the substance identity.

MCC-IMS may become a reliable, cost-effective, and rapid on-site screening tool for infectious pathogens. In future studies, not only different bacterial species but also viruses as well as breath should be investigated under the influence of different methodological factors.

Supplementary Information The online version contains supplementary material available at https://doi.org/10.1007/s00253-021-11315-w.

Acknowledgements We thank Lisa-Marie Bangen and Elisabeth Wenzel for excellent technical assistance and Nicole Pietzsch for supplying the resistant bacteria.

\section{Availability of data and material Available on reasonable request.}

Code availability Not applicable.

Author contribution IS designed the study, performed the experiments, collected and analyzed the data, drafted and reviewed the manuscript

JS contributed to study design and data analysis procedure, discussed results, edited and reviewed the manuscript

CS contributed to data analysis procedure and data analysis, reviewed the manuscript

DK funding, discussed design of the study and results, reviewed the manuscript

All authors read and approved the manuscript.

Funding Open Access funding enabled and organized by Projekt DEAL. The work was funded by the German Ministry of Education and Research (BMBF grant no. 03ZZ0812B).

\section{Declarations}

Ethics approval Studies with humans or animals as subjects were not carried out by any of the authors in this study.

Consent to participate Not applicable.

Consent for publication Not applicable.

Conflict of interest The authors declare no competing interests.

Open Access This article is licensed under a Creative Commons Attribution 4.0 International License, which permits use, sharing, adaptation, distribution and reproduction in any medium or format, as long as you give appropriate credit to the original author(s) and the source, provide a link to the Creative Commons licence, and indicate if changes were made. The images or other third party material in this article are included in the article's Creative Commons licence, unless indicated otherwise in a credit line to the material. If material is not included in the article's Creative Commons licence and your intended use is not permitted by statutory regulation or exceeds the permitted use, you will need to obtain permission directly from the copyright holder. To view a copy of this licence, visit http://creativecommons.org/licenses/by/4.0/.

\section{References}

Becher G, Purkhart R, Viertel B, Graupner R (2012) Device and method for analyzing volatile organic compounds in gaseous samples. DE201110106717;WO2012IB01924 G01N33/497

Becher G, Purkhart R, Raessler T, Schueler W, Steppert C (2016) An alternative method to the infection detection for differentiation of 3 and 4 MRGN germs by use of GC IMS. Eur Respir J 48:OA4993

Boots AW, Smolinska A, van Berkel JJBN, Fijten RRR, Stobberingh EE, Boumans MLL, Moonen EJ, Wouters EFM, Dallinga JW, van Schooten FJ (2014) Identification of microorganisms based on headspace analysis of volatile organic compounds by gas chromatography-mass spectrometry. J Breath Res 8:27106

Cumeras R, Figueras E, Davis CE, Baumbach JI, Gràcia I (2015) Review on ion mobility spectrometry. Part 1: current instrumentation. Analyst 140:1376-1390

Drees C, Vautz W, Liedtke S, Rosin C, Althoff K, Lippmann M, Zimmermann S, Legler TJ, Yildiz D, Perl T, Kunze-Szikszay N (2019) GC-IMS headspace analyses allow early recognition of bacterial growth and rapid pathogen differentiation in standard blood cultures. Appl Microbiol Biotechnol 103:9091-9101

Fiebig L, Beyene N, Burny R, Fast CD, Cox C, Mgode GF (2020) From pests to tests: training rats to diagnose tuberculosis. Eur Respir J 55: 1902243

Gunnink LB, Arouri DJ, Jolink FEJ, Lokate M, Jonge K de, Kampmeier S, Kreis C, Raschke M, Kleinjan M, Ter Maaten JC, Friedrich AW, Bathoorn E, Glasner C (2021) Compliance to screening protocols for multidrug-resistant microorganisms at the emergency departments of two academic hospitals in the Dutch-German CrossBorder Region. Trop Med Infect Dis 6

Hong-Geller E, Adikari S (2018) Volatile organic compound and metabolite signatures as pathogen identifiers and biomarkers of infectious disease. In: Rinken T, Kivirand K (eds) Biosensing technologies for the detection of pathogens - a prospective way for rapid analysis. InTech, pp 21-36

Hopfgartner G (2019) Current developments in ion mobility spectrometry. Anal Bioanal Chem 411:6227

Jünger M, Vautz W, Kuhns M, Hofmann L, Ulbricht S, Baumbach JI, Quintel M, Perl T (2012) Ion mobility spectrometry for microbial volatile organic compounds: a new identification tool for human pathogenic bacteria. Appl Microbiol Biotechnol 93:2603-2614

Khan K, Arino J, Hu W, Raposo P, Sears J, Calderon F, Heidebrecht C, Macdonald M, Liauw J, Chan A, Gardam M (2009) Spread of a novel influenza A (H1N1) virus via global airline transportation. N Engl J Med 361:212-214

Koivusalo M, Vermeiren C, Yuen J, Reeve C, Gadbois S, Katz K (2017) Canine scent detection as a tool to distinguish meticillin-resistant Staphylococcus aureus. J Hosp Infect 96:93-95

Küntzel A, Fischer S, Bergmann A, Oertel P, Steffens M, Trefz P, Miekisch W, Schubert JK, Reinhold P, Köhler H (2016) Effects of biological and methodological factors on volatile organic compound patterns during cultural growth of Mycobacterium avium ssp. paratuberculosis. J Breath Res 10:37103

Kunze N, Göpel J, Kuhns M, Jünger M, Quintel M, Perl T (2013) Detection and validation of volatile metabolic patterns over different strains of two human pathogenic bacteria during their growth in a complex medium using multi-capillary column-ion mobility spectrometry (MCC-IMS). Appl Microbiol Biotechnol 97:3665-3676

Kunze-Szikszay N, Walliser K, Luther J, Cambiaghi B, Reupke V, Dullin C, Vautz W, Bremmer F, Telgheder U, Zscheppank C, Quintel M, Perl T (2019) Detecting early markers of ventilator-associated pneumonia by analysis of exhaled gas. Crit Care Med 47:e234-e240

Kwiatkowski P, Łopusiewicz Ł, Pruss A, Kostek M, Sienkiewicz M, Bonikowski R, Wojciechowska-Koszko I, Dołęowska B (2020) Antibacterial activity of selected essential oil compounds alone 
and in combination with $\beta$-lactam antibiotics against MRSA strains. Int J Mol Sci 21:7106

Laupland KB, Valiquette L (2013) The changing culture of the microbiology laboratory. Can J Infect Dis Med Microbiol 24:125-128

Mathew TL, Pownraj P, Abdulla S, Pullithadathil B (2015) Technologies for clinical diagnosis using expired human breath analysis. Diagnostics (Basel) 5:27-60

Molton JS, Tambyah PA, Ang BSP, Ling ML, Fisher DA (2013) The global spread of healthcare-associated multidrug-resistant bacteria: a perspective from Asia. Clin Infect Dis 56:1310-1318

Olsen SJ, Chang H-L, Cheung TY-Y, Tang AF-Y, Fisk TL, Ooi SP-L, Kuo H-W, Jiang DD-S, Chen K-T, Lando J, Hsu K-H, Chen T-J, Dowell SF (2003) Transmission of the severe acute respiratory syndrome on aircraft. N Engl J Med 349:2416-2422

Peacock SJ, Paterson GK (2015) Mechanisms of methicillin resistance in Staphylococcus aureus. Annu Rev Biochem 84:577-601

Pereira J, Silva CL, Perestrelo R, Gonçalves J, Alves V, Câmara JS (2014) Re-exploring the high-throughput potential of microextraction techniques, SPME and MEPS, as powerful strategies for medical diagnostic purposes. Innovative approaches, recent applications and future trends. Anal Bioanal Chem 406:2101-2122

Purkhart R (2010) Klassifikation von Ausatemluft anhand ihrer differenziellen Ionenbeweglichkeitsspektrogramme. Diploma Thesis, Berlin

Purkhart R, Köhler H, Liebler-Tenorio E, Meyer M, Becher G, Kikowatz A, Reinhold P (2011) Chronic intestinal Mycobacteria infection: discrimination via VOC analysis in exhaled breath and headspace of feces using differential ion mobility spectrometry. J Breath Res 5: 27103

Purkhart R, Becher G, Reinhold P, Köhler HU (2017) Detection of mycobacteria by volatile organic compound analysis of in vitro cultures using differential ion mobility spectrometry. J Med Microbiol 66:276-285

Ratiu I-A, Ligor T, Bocos-Bintintan V, Al-Suod H, Kowalkowski T, Rafińska K, Buszewski B (2017) The effect of growth medium on an Escherichia coli pathway mirrored into GC/MS profiles. J Breath Res 11:36012

Rees CA, Nasir M, Smolinska A, Lewis AE, Kane KR, Kossmann SE, Sezer O, Zucchi PC, Doi Y, Hirsch EB, Hill JE (2018) Detection of high-risk carbapenem-resistant Klebsiella pneumoniae and Enterobacter cloacae isolates using volatile molecular profiles. Sci Rep 8:13297

Ruszkiewicz DM, Sanders D, O'Brien R, Hempel F, Reed MJ, Riepe AC, Bailie K, Brodrick E, Darnley K, Ellerkmann R, Mueller O, Skarysz A, Truss M, Wortelmann T, Yordanov S, Thomas CLP, Schaaf B, Eddleston M (2020) Diagnosis of COVID-19 by analysis of breath with gas chromatography-ion mobility spectrometry - a feasibility study. EClinicalMedicine 29:100609

Sahota AS, Gowda R, Arasaradnam RP, Daulton E, Savage RS, Skinner JR, Adams E, Ward SA, Covington JA (2016) A simple breath test for tuberculosis using ion mobility: a pilot study. Tuberculosis (Edinb) 99:143-146

Shirasu M, Touhara K (2011) The scent of disease: volatile organic compounds of the human body related to disease and disorder. J Biochem 150:257-266

Stach J, Baumbach JI (2002) Ion mobility spectrometry—basic elements and applications. Int J Ion Mobil Spectrom 5:1-21

Steppert I (2013) Diskriminierung verschiedener Bakterienspezies mittels Ionenmobilitätsspektrometrie. Bachelor Thesis, Coburg

Steppert C, Dick T, Steppert I, Bollinger T, Becher G (2018) Rapid in vitro detection of resistant strains by MCC-IMS. Eur Respir J 52:PA2655

Szymańska E, Davies AN, Buydens LMC (2016) Chemometrics for ion mobility spectrometry data: recent advances and future prospects. Analyst 141:5689-5708

Tenover FC (2006) Mechanisms of antimicrobial resistance in bacteria. Am J Infect Control 34:S3-S10 discussion S64-73

Traxler S, Bischoff A-C, Saß R, Trefz P, Gierschner P, Brock B, Schwaiger T, Karte C, Blohm U, Schröder C, Miekisch W, Schubert JK (2018) VOC breath profile in spontaneously breathing awake swine during Influenza A infection. Sci Rep 8:14857

van Belkum A, Durand G, Peyret M, Chatellier S, Zambardi G, Schrenzel J, Shortridge D, Engelhardt A, Dunne WM (2013) Rapid clinical bacteriology and its future impact. Ann Lab Med 33:14-27

Westhoff M, Litterst P, Freitag L, Urfer W, Bader S, Baumbach J-I (2009) Ion mobility spectrometry for the detection of volatile organic compounds in exhaled breath of patients with lung cancer: results of a pilot study. Thorax 64:744-748

Wilde MJ, Cordell RL, Salman D, Zhao B, Ibrahim W, Bryant L, Ruszkiewicz D, Singapuri A, Free RC, Gaillard EA, Beardsmore C, Thomas CLP, Brightling CE, Siddiqui S, Monks PS (2019) Breath analysis by two-dimensional gas chromatography with dual flame ionisation and mass spectrometric detection - Method optimisation and integration within a large-scale clinical study. J Chromatogr A 1594:160-172

Wilson AD (2015) Advances in electronic-nose technologies for the detection of volatile biomarker metabolites in the human breath. Metabolites 5:140-163

Publisher's note Springer Nature remains neutral with regard to jurisdictional claims in published maps and institutional affiliations. 